\title{
Mid-Term Results of Computer-Assisted Cervical Pedicle Screw Fixation
}

\author{
Masashi Uehara, Jun Takahashi, Keijiro Mukaiyama, Shugo Kuraishi, \\ Masayuki Shimizu, Shota Ikegami, Toshimasa Futatsugi, Nobuhide Ogihara, \\ Hiroyuki Hashidate, Hiroki Hirabayashi, Hiroyuki Kato \\ Department of Orthopaedic Surgery, Shinshu University School of Medicine, Matsumoto, Japan
}

\begin{abstract}
Study Design: A retrospective study.
Purpose: The present study aimed to evaluate mid-term results of cervical pedicle screw (CPS) fixation for cervical instability.

Overview of Literature: CPS fixation has widely used in the treatment of cervical spinal instability from various causes; however, there are few reports on mid-term surgical results of CPS fixation.

Methods: Record of 19 patients who underwent cervical and/or upper thoracic (C2-T1) pedicle screw fixation for cervical instability was reviewed. The mean observation period was 90.2 months. Evaluated items included Japanese Orthopaedic Association (JOA) score and C2-7 lordotic angle before surgery and at 5 years after surgery. Postoperative computerized tomography was used to determine the accuracy of screw placement. Visual analog scale (VAS) for neck pain and radiological evidence of adjacent segment degeneration (ASD) at the 5-year follow-up were also evaluated.

Results: Mean JOA score was significantly improved from 9.0 points before surgery to 12.8 at 5 years after surgery ( $p=0.001)$. The C2-7 lordotic angle of the neutral position improved from $6.4^{\circ}$ to $7.8^{\circ}$ at 5 years after surgery, but this was not significant. The major perforation rate was $5.0 \%$. There were no clinically significant complications such as vertebral artery injury, spinal cord injury, or nerve root injury caused by any screw perforation. Mean VAS for neck pain was 49.4 at 5 years after surgery. The rate of ASD was $21.1 \%$. Conclusions: Our mid-term results showed that CPS fixation was useful for treating cervical instability. Severe complications were prevented with the assistance of a computed tomography-based navigation system.
\end{abstract}

Keywords: Cervical pedicle screw; Cervical instability; Mid-term results; Adjacent segment degeneration

\section{Introduction}

Cervical pedicle screw (CPS) placement was introduced in the early 1990s. It offers greater fixation strength than lateral mass screw placement, as it allows fixation from the posterior column to the anterior vertebral body. CPS fixation is sometimes used in the treatment of various degenerative, traumatic and developmental spinal conditions for potentially excellent biomechanical fixation and deformity correction [1]. However, CPS fixation has been critiqued for its potential risks of serious injury to neurovascular structures such as the spinal cord, nerve root and vertebral artery. To avoid such serious risks, we have performed CPS fixation combined with poste-

Received Dec 6, 2013; Revised Apr Jan 29, 2014; Accepted Feb 4, 2014

Corresponding author: Jun Takahashi

Department of Orthpaedic Surgery, Shinshu University School of Medicine, 3-1-1 Asahi, Matsumoto 390-8621, Japan

Tel: +81-263-37-2659, Fax: +81-263-35-8844, E-mail: jtaka@shinshu-u.ac.jp 
rior decompression under computed tomography (CT)based navigation system [2-4]. There are many reports on short-term surgical results of CPS fixation, with only a few studies on mid-term results.

Chronic neck pain due to decreased lordotic angle of the cervical spine and adjacent segment degeneration (ASD) has been reported after cervical spine fusion in long-term follow-up [5]. The reports regarding ASD involved anterior cervical decompression and fusion (ACDF), while ASD after CPS fixation was not reported. Furthermore, there were few reports concerning axial pain after CPS fixation. This study aimed to evaluate midterm clinical and radiological results of computer-assisted CPS fixation combined with laminoplasty for cervical instability.

\section{Materials and Methods}

With approval of the investigational review board of our hospital (No. 2188), records of nineteen patients (13 males, 6 female; mean age, $58.3 \pm 13.0$ years) who underwent cervical and/or upper thoracic (C2-T1) pedicle screw fixation, combined with posterior decompression for cervical instability, from September 1997 to November 2007, were analyzed. Consecutive patients with follow-up duration of five-year or more were included in this study. This surgical treatment was indicated for patients with destructive disease such as rheumatoid arthritis (RA) and destructive spondyloarthropathy (DSA) or cervical myelopathy caused by spinal cord compression and cervical instability.

Diseases included DSA in four patients, spine tumor in four patients, cervical spondylotic myelopathy with instability in three patients, cervical spondylotic myelopathy associated with athetoid cerebral palsy in three, RA in three and cervical trauma in two. The fusion levels were $\mathrm{C} 2-\mathrm{C} 3$ in one patient, $\mathrm{C} 2-\mathrm{C} 5$ in two, C2-C6 in two, C2$\mathrm{C} 7$ in one, $\mathrm{C} 3-\mathrm{C} 4$ in two, $\mathrm{C} 3-\mathrm{C} 5$ in two, $\mathrm{C} 3-\mathrm{C} 7$ in four, $\mathrm{C} 3-\mathrm{T} 1$ in one, $\mathrm{C} 4-\mathrm{C} 7$ in one, $\mathrm{C} 5-\mathrm{C} 6$ in one, $\mathrm{C} 5-\mathrm{C} 7$ in one and $\mathrm{C} 6-\mathrm{C} 7$ in one. The mean number for the fused level was $2.8 \pm 1.4$ intervertebral levels (range, 1 to 5 levels) (Table 1).

\section{Surgical technique}

We used a CT-based navigation system (Stealth Station and Stealth Station TREONTM, Medtronic, Sofamor
Danek, Memphis, TN, USA). We established a pre-surgical plan and obtained information, including diameter/ length of screws that could be inserted. For pedicles to which a screw could be securely inserted, angles to internal sides were obtained, and pedicles were evaluated and marked. In cases of unilateral occlusion of vertebral artery with narrow pedicle on the dominant side, we did not attempt to insert a CPS. In screw insertion, the operation field was opened to one vertebra above and one below the vertebra to be fixed, and to the spinous process, lamina and lateral mass. Only for vertebrae with no instability, registration was performed on two vertebrae continuously to shorten the registration time. Insertion points were checked using the navigation probe, and the insertion point was prepared using a $3-\mathrm{mm}$ diamond bar. The screw hole was then prepared, using Kotani's probe [6]. The wall was scouted by sounding, and a tap hole made using a under tap $(0.5 \mathrm{~mm})$ to a depth $5-\mathrm{mm}$ shorter than the planned insertion depth. Then, the wall was again scouted by sounding, and CPS inserted. As the screw can easily perforate to the lateral side because of the thinness of the pedicle wall and pressure on the screwdriver from paravertebral muscle during screw insertion, an additional procedure such as making another skin incision from the outer side and inserting a screw from that incision was sometimes required.

Expansive open-door laminoplasty [7] was performed in affected spinal cord levels. Holes were made using a 2-mm-diameter diamond speed drill in each of the lamina, and a suture was passed through the hole and tied to hinge the side rod. Minced autologous bone was placed between the laminas, and the suture was securely tied. Patients were permitted to ambulate the day after surgery without a neck collar.

\section{Clinical evaluation}

Clinical symptoms before and at five-year after surgery were evaluated according to Japanese Orthopaedic Association (JOA) scores. The recovery rate was calculated using the method of Hirabayashi et al. [7], which compared preoperative and postoperative JOA scores according to the following equation:

recovery rate $(\%)=$ (postoperative score-preoperative score $) \times 100 /$ (full score-preoperative score).

Neck pain was evaluated using visual analog scale (VAS; $0=$ no pain, $100=$ worst imaginable pain). 
Table 1. Clinical profile and details of surgical procedures

\begin{tabular}{|c|c|c|c|c|c|c|c|c|c|c|}
\hline \multirow[b]{2}{*}{ Case } & \multirow{2}{*}{$\begin{array}{c}\text { Age at } \\
\text { surgery } \\
\text { (yr) }\end{array}$} & \multirow[b]{2}{*}{ Gender } & \multirow[b]{2}{*}{ Disease } & \multirow[b]{2}{*}{$\begin{array}{l}\text { Range of } \\
\text { fusion }\end{array}$} & \multirow[b]{2}{*}{$\begin{array}{l}\text { Follow-up } \\
\text { (mo) }\end{array}$} & \multicolumn{2}{|c|}{ JOA score } & \multicolumn{2}{|c|}{ C2-7 angle } & \multirow[b]{2}{*}{ Complications } \\
\hline & & & & & & Preop & $\begin{array}{l}\text { Post } \\
5 \text { year }\end{array}$ & Preop & $\begin{array}{l}\text { Post } \\
5 \text { year }\end{array}$ & \\
\hline 1 & 66 & Male & Trauma & C5-C7 & 156 & 0 & 4.5 & -10 & -8 & \\
\hline 2 & 71 & Male & DSA & C3-C7 & 130 & 3.5 & 14 & 39 & 35 & \\
\hline 3 & 55 & Male & CSM & C6-C7 & 62 & 13 & 15 & 18 & 20 & \\
\hline 4 & 61 & Male & DSA & C3-C7 & 75 & $\mathrm{~N}$ & $\mathrm{~N}$ & 27 & 39 & \\
\hline 5 & 54 & Male & DSA & C3-C7 & 71 & 9 & $\mathrm{~N}$ & -5 & 9 & Implant failure \\
\hline 6 & 76 & Male & CSM & C5-C6 & 140 & 15.5 & 16.5 & 15 & 14 & \\
\hline 7 & 61 & Male & Tumor & C2-C6 & 150 & 12 & 17 & 22 & 1 & \\
\hline 8 & 46 & Male & Tumor & C2-C5 & 144 & $\mathrm{~N}$ & 16.5 & -5 & -13 & \\
\hline 9 & 60 & Female & Tumor & C2-C6 & 69 & 6 & 14 & -2 & 4 & C5 palsy \\
\hline 10 & 33 & Male & CP & C2-C5 & 87 & 9 & 12 & -6 & 32 & \\
\hline 11 & 69 & Female & Tumor & C3-T1 & 82 & 17 & $N$ & 3.9 & 11 & \\
\hline 12 & 43 & Male & $\mathrm{CP}$ & C2-C7 & 90 & 3.5 & 6 & 28 & -12 & \\
\hline 13 & 57 & Female & RA & C3-C4 & 72 & 14 & 16.5 & -5 & -10 & \\
\hline 14 & 69 & Male & $\mathrm{CP}$ & C3-C7 & 73 & 7.5 & 11 & -4 & 5.6 & \\
\hline 15 & 71 & Female & CSM & C3-C5 & 72 & 11.5 & 11.5 & -11 & -2 & \\
\hline 16 & 29 & Female & Trauma & C2-C3 & 60 & 7.5 & $\mathrm{~N}$ & 9 & 12 & \\
\hline 17 & 53 & Male & DSA & C4-C7 & 60 & 7 & 17 & 2 & -2 & C5 palsy \\
\hline 18 & 67 & Male & $\mathrm{RA}$ & C3-C5 & 60 & 11 & 13.5 & -5 & -5 & SSI \\
\hline 19 & 67 & Female & RA & C3-C4 & 60 & 6 & 7.5 & 10 & 18 & \\
\hline Mean & 58.3 & & & & 90.2 & 9.0 & 12.8 & 6.4 & 7.8 & \\
\hline
\end{tabular}

JOA, Japanese Orthopaedic Association; Preop, preoperative; Post, postoperative; DSA, destructive spondyloarthropathy; CSM, cervical spondylotic myelopathy; N, none; CP, cervical spondylotic myelopathy associated with athetoid cerebral palsy; RA, rheumatoid arthritis; SSI, surgical site infection.

\section{Radiographic evaluation}

Cervical sagittal alignment (i.e., the $\mathrm{C} 2-7$ lordotic angle) was measured according to tangential lines placed on the posterior edges of the $\mathrm{C} 2$ and $\mathrm{C} 7$ vertebral bodies on lateral X-ray in a neutral position. Radiological evidence of ASD was determined by pre-established criteria as follows: new anterior osteophyte formation or enlargement of existing osteophytes, increased or new narrowing of a disc space (>30\%); new or increased calcification of the anterior longitudinal ligament; and formation of radial osteophytes [8]. All patients underwent reconstruction CT scans of instrumented levels after surgery. Pedicle screw perforation of cervical pedicles was evaluated by axial CT images with a slice thickness of $1.25 \mathrm{~mm}$ (Siemens SOMATOM Sensation 16, Siemens Asahi Meditec
Inc., Shinagawa, Tokyo, Japan). Screw insertion status was classified as: grade 1 (no perforation), indicating that the screw was accurately inserted in pedicle; grade 2 (minor perforation), indicating perforation of less than 50\% of the screw diameter; and grade 3 (major perforation), indicating perforation of $50 \%$ of screw diameter or more. The analysis of radiograph was performed by independent investigator. Interlaminar fusion was defined as a union when radiographs indicated bilateral continuity in the fusion mass between the laminae (with $<2^{\circ}$ of angular motion) and when lateral flexion-extension radiographs showed the absence of translation between the vertebrae at the level of bone transplantation. The reported surgical complications, the surgical times and the estimated blood loss volumes were also analyzed. The data were analyzed by Wilcoxon signed rank sum test using SPSS software 
(SPSS Japan Inc., IBM, Tokyo, Japan). The level of significance was set at $p<0.05$.

\section{Results}

The follow-up period ranged from 60 to 156 months (mean, 90.2 \pm 34.5 months). None of the nineteen patients had died at the final follow-up. The average surgical time was $316 \pm 137$ minutes (range, 122-600 minutes). The average blood loss was $721 \pm 1,080 \mathrm{~mL}$ (range, 100-4,600 $\mathrm{mL}$ ). In total, complications were reported in four cases: C5 palsy, which was observed in two patients (10.5\%); implant failure of screw pull-out, which was observed in one patient (5.3\%); surgical site infection, which was observed in one patient (5.3\%); and severe blood loss $(>2,000 \mathrm{~mL})$, which was observed in one patient $(5.3 \%)$. None of these patients required a revision surgery, as the complications were not severe and there were no complaints.

The mean JOA scores (full score, 17 points) before and five-year after surgery were $9.0 \pm 4.6$ (range, $0-15.5$ ) and $12.8 \pm 4.1$ points (range, $4.5-17$ points), respectively. The

(A)
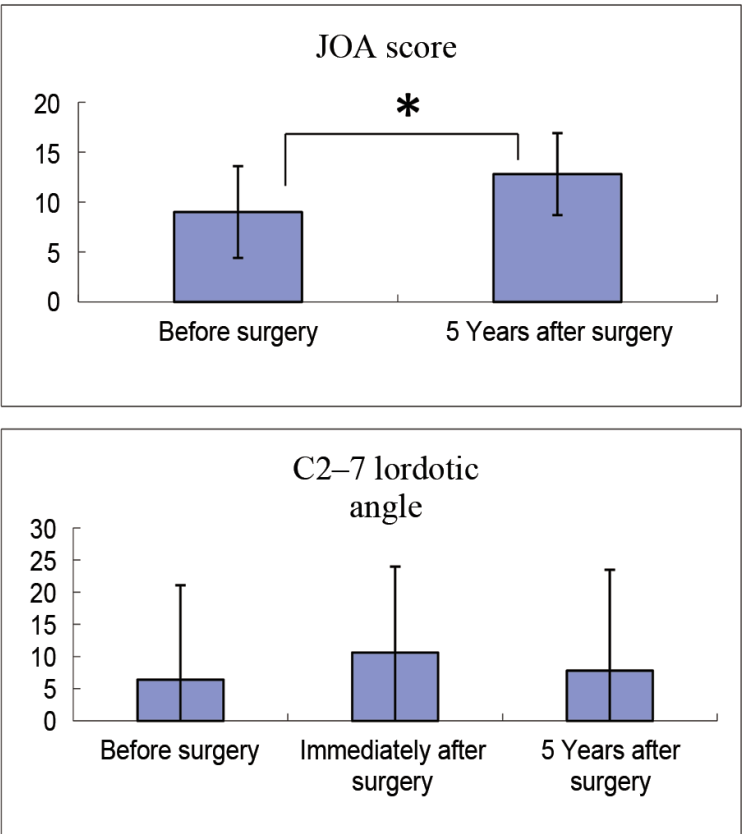

Fig. 1. Japanese Orthopaedic Association (JOA) scores and radiological evaluation for C2-7 lordotic angle. (A) Mean JOA score was significantly improved from $9.0 \pm 4.6$ points before surgery to $12.8 \pm 4.1$ at five-year after surgery $(p=0.001)$. (B) The mean $\mathrm{C} 2-7$ lordotic angle in the neutral position improved from $6.4^{\circ} \pm 14.7^{\circ}$ to $10.6^{\circ} \pm 13.4^{\circ}$ (range, $-7^{\circ}$ to $41^{\circ}$ ) immediately after surgery and $7.8^{\circ} \pm 15.7^{\circ}$ at five-year after surgery, but this was not significant $(p=0.338) .{ }^{*} p<0.05$. mean JOA score at the five-year follow-up was significantly improved, compared to the mean preoperative score $(p=0.001)$ (Fig. 1A). The improvement rate of JOA scores five-year after surgery was $51.8 \% \pm 32.1 \%$ (range, $0-100 \%$ ). Mean VAS for neck pain was $49.4 \pm 28.0$ (range, $0-80)$ at five-year after surgery.

A total of one hundred screws were inserted transpedicularly from $\mathrm{C} 2$ to $\mathrm{T} 1$, with assistance of a CT-based navigation system. The rate of grade 3 pedicle screw perforations was $5.0 \%(5 / 100)$, whereas the combined rate of grade 2 and 3 perforations was 14.0\% (14/100). There were no clinically significant complications such as vertebral artery injury, spinal cord injury or nerve root injury caused by any screw perforation. The evaluation was performed separately in C2, C3 to C6, and C7 to T1. The perforation rate of grade 3 was $18.2 \%(2 / 11)$ in C2. The perforation rate of grade 3 was $2.8 \%(2 / 72)$ in C3 to C6. The perforation rate of grades 2 and 3 was 13.9\% (10/72) in C3 to C6. The perforation rate of grade 3 was 5.9\% $(1 / 17)$ in $\mathrm{C} 7$ to T1. The perforation rate of grades 2 and 3 was $11.8 \%$ (2/17) in C7 to T1. The mean C2-7 lordotic angle of the neutral position improved from $6.4^{\circ} \pm 14.7^{\circ}$ (range, $-11^{\circ}$ to $39^{\circ}$ ) to $10.6^{\circ} \pm 13.4^{\circ}$ (range, $-7^{\circ}$ to $41^{\circ}$ ) immediately after surgery and $7.8^{\circ} \pm 15.7^{\circ}$ (range, $-13^{\circ}$ to $\left.39^{\circ}\right)$ at five-year after surgery, but these were not significant $(p=0.144,0.338)$ (Fig. 1B). We evaluated separately in categories of short fusion ( $<3$ intervertebral) and long fusion. $\mathrm{C} 2-7$ lordotic angle in short fusion was improved from $2.6^{\circ} \pm 11.6^{\circ}$ to $7.0^{\circ} \pm 13.9^{\circ}(p=0.128)$ immediately after surgery and $4.9^{\circ} \pm 12.4^{\circ}(p=0.176)$ at five-year after surgery. $\mathrm{C} 2-7$ lordotic angle in long fusion was improved from $9.1^{\circ} \pm 16.5^{\circ}$ to $13.2^{\circ} \pm 13.0^{\circ}$ ( $\left.p=0.476\right)$ immediately after surgery and $10.0^{\circ} \pm 18.0^{\circ}(p=0.656)$ at five-year after surgery. Bony union was noted in $94.7 \%(18 / 19)$ of patients. The rate of ASD in the follow-up period was $21.1 \%$ (4/19), but there was no patient who needed revision surgery for ASD.

\section{Case study}

1) Case 17: a 53-year-old man with DSA

A preoperative radiograph and magnetic resonance imaging showed spinal cord compression from $\mathrm{C} 4$ to $\mathrm{C} 6$ with cervical instability at C4/C5 (Figs. 2, 3). C2-7 lordotic angle was $2^{\circ}$. Preoperative JOA score was 7 points. CPS fixation with spinal cord decompression from $\mathrm{C} 4$ to C7 was performed. C2-7 lordotic angle was corrected to 

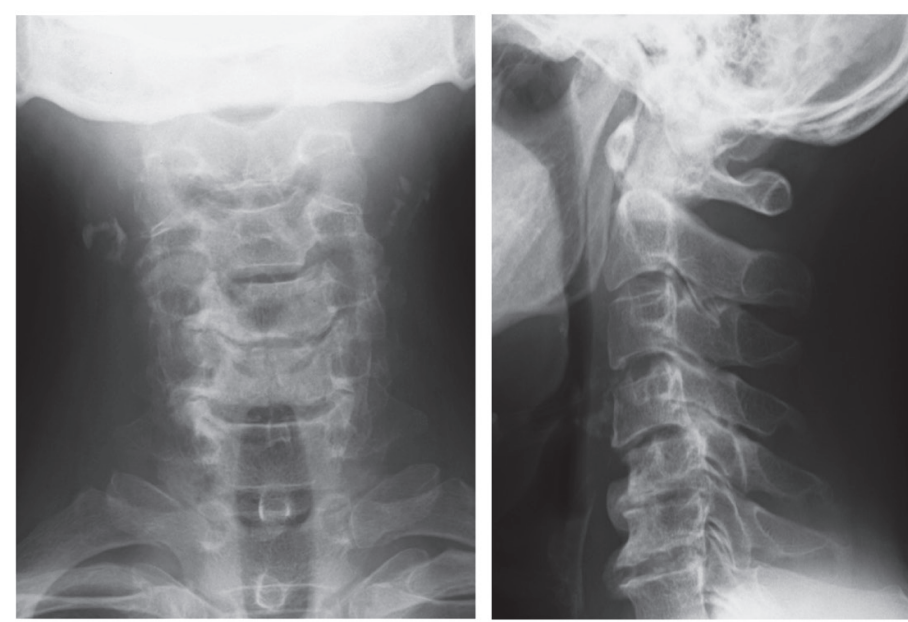

Neutral

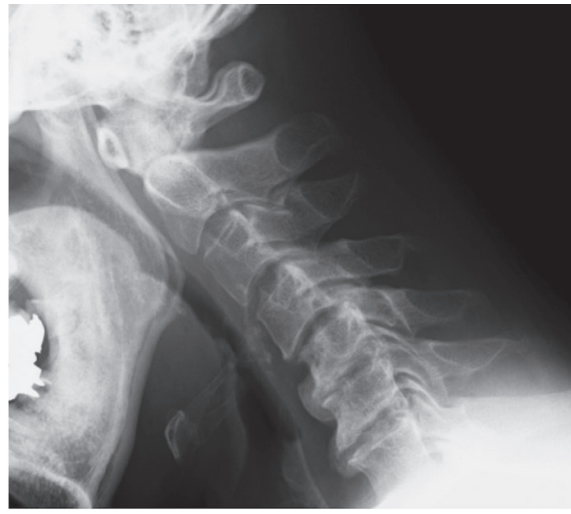

Flexion

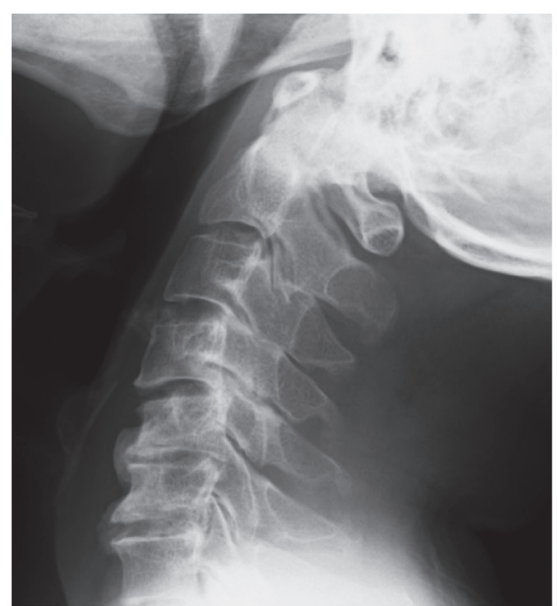

Extension

Fig. 2. Preoperative radiographs. Preoperative radiograph showed cervical instability at $\mathrm{C} 4 / 5$ intervertebral level.

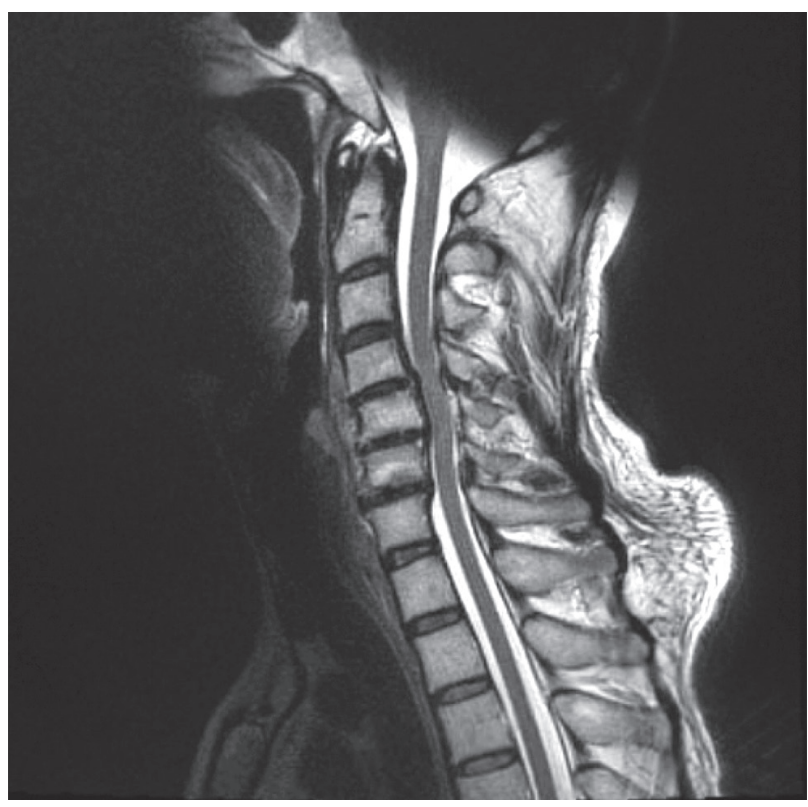

Fig. 3. Preoperative magnetic resonance imaging (MRI). A preoperative MRI showed spinal cord compression from C4 to C6, with a high signal change at $\mathrm{C} 4 / 5$ inter vertebral level. $13^{\circ}$ at immediately after surgery (Fig. 4). At five-year after surgery, $\mathrm{C} 2-7$ lordotic angle was $-2^{\circ}$, and JOA score was 17 points (Fig. 5).

\section{Discussion}

Cervical spinal fixation using CPS for cervical instability caused by cervical trauma was first described Abumi et al. [9] and Jeanneret et al. [10] in 1994. The indications for CPS have since been extended and now include conditions such as RA, DSA and spinal tumor [11-13]. CPS can achieve better rigid fixation than other cervical fixation methods and can be combined with posterior spinal cord decompression. However, CPS insertion is technically demanding because of the narrow pedicle diameter, and there are risks of serious neurovascular complications including vertebral artery tear, spinal cord injury and nerve root injury [14]. To avoid these serious neurovascular complications, we used a CT-based navigation system [2- 

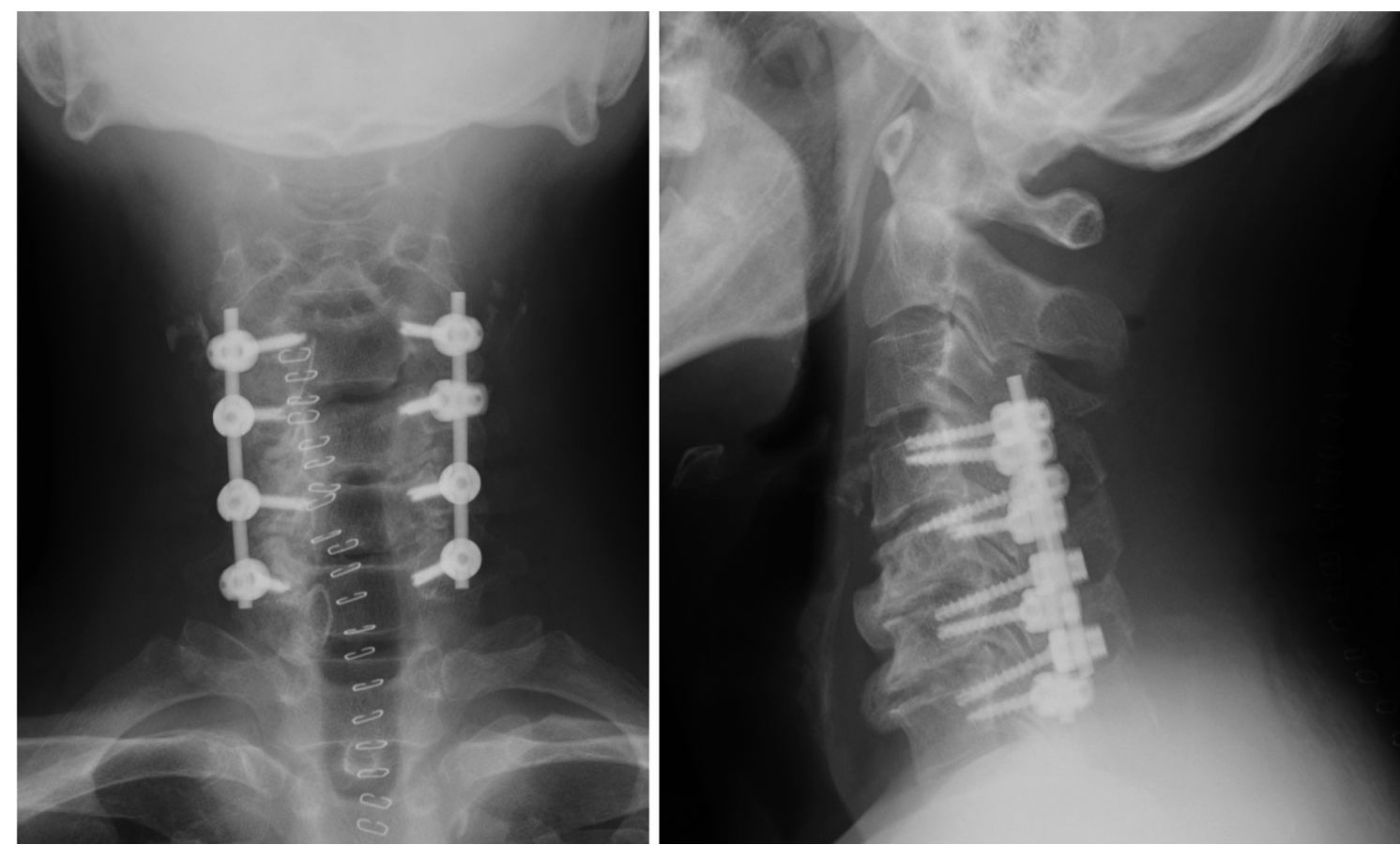

Fig. 4. Radiographs at immediately after surgery. C2-7 lordotic angle was corrected to $13^{\circ}$ immediately after surgery.
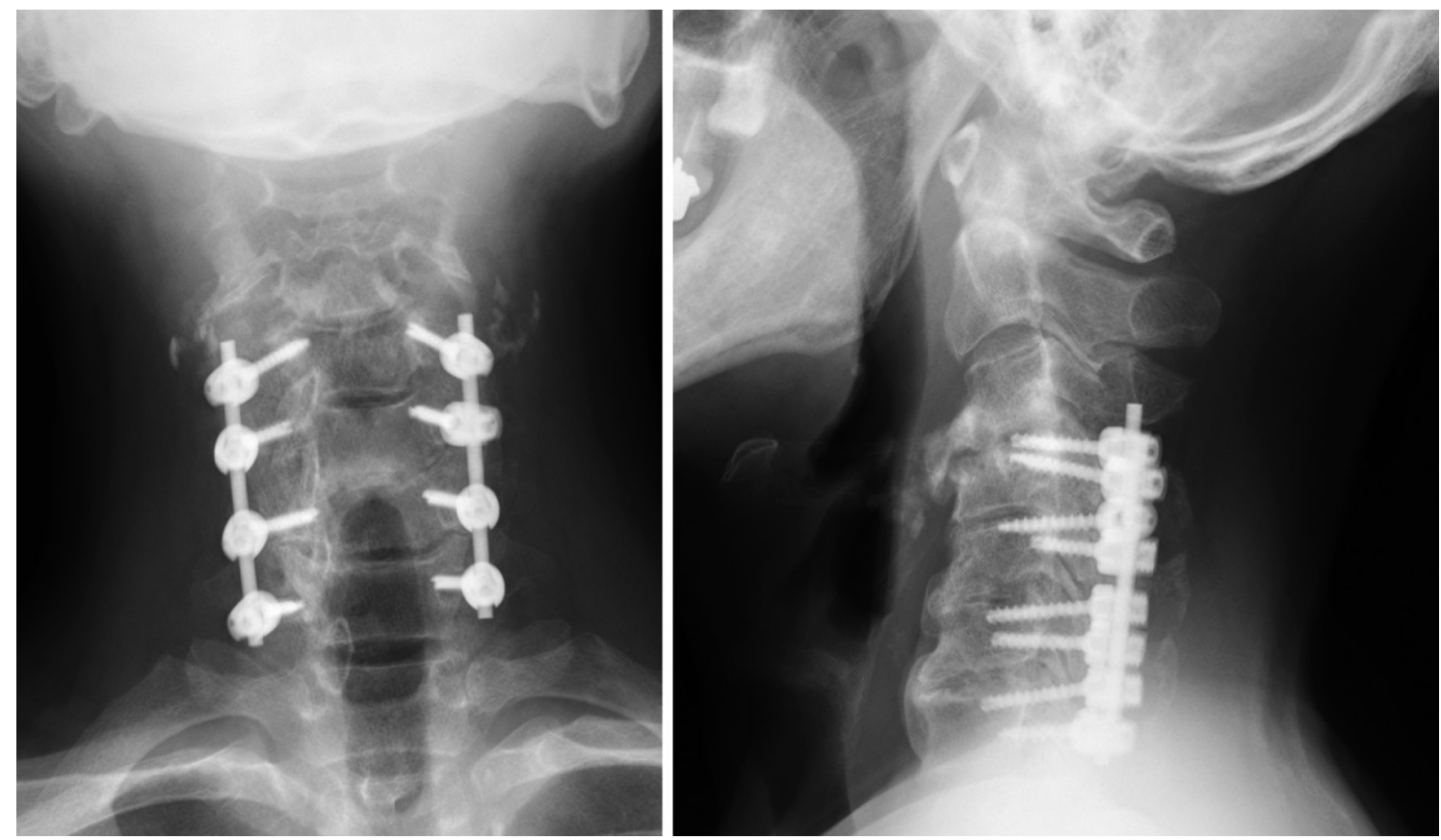

Fig. 5. Radiographs at five-year after surgery. At five-year after surgery, radiographs showed C2-7 lordotic angle of $-2^{\circ}$, and Japanese Orthopaedic Association score was 17 points.

4]. CPS perforation rate in our study was as low as in previous reports (Table 2) [15-19]. In the patients selected for our study, the mean JOA score was significantly improved at five-year after cervical reconstruction by CPS fixation without serious neurovascular complications. In some cases, blood loss may be extensive and surgical time long. Blood loss and surgical times were greater during the introduction period of the CT-based navigation 
Table 2. Previous reports of perforation rates

\begin{tabular}{|c|c|c|c|c|c|}
\hline \multirow{2}{*}{ Author } & \multirow{2}{*}{ Year } & \multirow{2}{*}{$\mathrm{n}$} & \multicolumn{2}{|c|}{ Perforation rate $(\%)$} & \multirow{2}{*}{ Technique } \\
\hline & & & Major & Major+minor & \\
\hline Yukawa et al. [15] & 2009 & 144 & 3.9 & 13.1 & Fluoroscopy \\
\hline Ishikawa et al. [16] & 2010 & 30 & 12.7 & 27 & Fluoroscopy \\
\hline Ishikawa et al. & 2010 & 32 & 3.3 & 18.6 & 3D fluoroscopy-based \\
\hline Lee et al. [17] & 2012 & 48 & 5.4 & 29.2 & Fluoroscopy \\
\hline Tofuku et al. [18] & 2012 & 32 & 3.9 & 11.7 & Fluoroscopy \\
\hline Tauchi et al. [19] & 2013 & 46 & 12.2 & - & CT-based \\
\hline Current study & & 100 & 5.0 & 14.0 & CT-based \\
\hline
\end{tabular}

3D, 3-dimensional; CT, computed tomography.

system. There was a learning curve for this procedure, and blood loss and surgical times were reduced with experience. The patient in whom 4,600 mL of blood loss was reported had multiple myeloma in the $\mathrm{C} 4$ vertebra. We treated this patient with posterior CPS fixation between C2 and C6. In particular, subtotal spondylectomy and vertebral body replacement were performed. As the blood loss during tumor resection was high, we did not consider that the blood loss resulted from vertebral artery injury. Another reason for the high blood loss could be that the surgeon was not experienced with CPS fixation, as this surgery was performed at the time of introduction of the procedure.

In previous reports, VAS for neck pain after cervical spinal surgery was 16 to 41 in patients with ACDF [20,21] and 9 to 49.7 in patients with laminoplasty [22-24]. VAS for neck pain was a little higher than previous reports in our study. We regarded the neck pain after surgery as a weak point of CPS fixation due to the necessity to release the lateral side of lateral mass and the longer skin incision, compared to laminoplasty. Andaluz et al. [5] reported a $30.8 \%$ incidence of chronic neck pain during long-term follow-up, $75 \%$ of which developed in patients with postoperative kyphosis. A significant relationship between postoperative C2-7 regional kyphosis and chronic neck pain was also noted. McAviney et al. [25] reported a normal range for the $\mathrm{C} 2-7$ lordotic angle to be $31^{\circ}$ to $40^{\circ}$; and they found a statistically significant association between cervical pain and lordosis $<20^{\circ}$. In our study, the $\mathrm{C} 2-7$ lordotic angle was improved after CPS fixation, but it was not a significant improvement. We think that cervical alignment correction by CPS fixation may not be enough, and it may be better to preoperatively correct the lordotic angle by Mayfield head holders with radiographic image.

ASD is a common complication after spine surgery in long-term follow up. ASD is defined by asymptomatic new radiographic evidence. Baba et al. [26] followed 106 patients after ACDF and found that more than 25\% developed ASD within 8.5 years of follow-up. Gore and Sepic [27] reported that of 125 patients of anterior cervical fusion with five-year follow-up, ASD developed in $25 \%$ and preoperative ASD worsened in $25 \%$. Although ACDF is often beneficial at the fused segment, it may initiate or accelerate ASD [26]. The risks of developing new symptoms secondary to adjacent segment pathology causing radiculopathy and/or myelopathy after cervical fusion surgery range from a cumulative rate of $1.6 \%$ to $4.2 \%$ per year. In our study, $21.1 \%$ of patients had ASD, as observed in the follow-up period. The rate of ASD in our study was lower than in previous reports regarding ACDF. No patient complained of symptoms due to ASD, and no revision surgery was necessary.

C5 palsy is another well-known potential complication of cervical spine surgery, with reported rates ranging from $0 \%$ to $30 \%[28,29]$. The palsy is typically unilateral, but the condition is bilateral in 5\% to $7 \%$ [30]. It is manifested by paresis of the deltoid and/or biceps brachii muscle, sensory deficits and/or intractable pain in the shoulders. In the present study, two patients (10.5\%) had C5 palsy that eventually was improved in both patients.

The limitations of this study included a lack of control group, small sample size, various diseases, various fusion levels and retrospective design. On the basis of the analysis 
of mid-term outcomes in nineteen patients, we concluded that CPS fixation with a CT-based navigation system was effective in the treatment of cervical instability.

\section{Conclusions}

In our study, the mean JOA score significantly improved at five-year after cervical pedicle screw fixation without serious complications. Mean visual analog scale for neck pain was $49.4 \pm 28.0$ at five-year after surgery. The rate of ASD in the follow-up period was $21.1 \%$ (4/19). Our midterm results showed that cervical pedicle screw fixation was useful for treating cervical instability. Severe complications could be prevented by using a CT-based navigation system.

\section{Conflict of Interest}

No potential conflict of interest relevant to this article was reported.

\section{References}

1. Gaines RW Jr. The use of pedicle-screw internal fixation for the operative treatment of spinal disorders. J Bone Joint Surg Am 2000;82:1458-76.

2. Uehara M, Takahashi J, Hirabayashi H, et al. Perforation rates of cervical pedicle screw insertion by disease and vertebral level. Open Orthop J 2010;4:142-6.

3. Takahashi J, Shono Y, Nakamura I, et al. Computerassisted screw insertion for cervical disorders in rheumatoid arthritis. Eur Spine J 2007;16:485-94.

4. Uehara M, Takahashi J, Ogihara N, et al. Cervical pedicle screw fixation combined with laminoplasty for cervical spondylotic myelopathy with instability. Asian Spine J 2012;6:241-8.

5. Andaluz N, Zuccarello M, Kuntz C. Long-term follow-up of cervical radiographic sagittal spinal alignment after 1- and 2-level cervical corpectomy for the treatment of spondylosis of the subaxial cervical spine causing radiculomyelopathy or myelopathy: a retrospective study. J Neurosurg Spine 2012;16:2-7.

6. Kotani Y, Abumi K, Ito M, Minami A. Improved accuracy of computer-assisted cervical pedicle screw insertion. J Neurosurg 2003;99:257-63.

7. Hirabayashi K, Watanabe K, Wakano K, Suzuki N,
Satomi K, Ishii Y. Expansive open-door laminoplasty for cervical spinal stenotic myelopathy. Spine (Phila Pa 1976) 1983;8:693-9.

8. Robertson JT, Papadopoulos SM, Traynelis VC. Assessment of adjacent-segment disease in patients treated with cervical fusion or arthroplasty: a prospective 2-year study. J Neurosurg Spine 2005;3:41723.

9. Abumi K, Itoh H, Taneichi H, Kaneda K. Transpedicular screw fixation for traumatic lesions of the middle and lower cervical spine: description of the techniques and preliminary report. J Spinal Disord 1994;7:19-28.

10. Jeanneret B, Gebhard JS, Magerl F. Transpedicular screw fixation of articular mass fracture-separation: results of an anatomical study and operative technique. J Spinal Disord 1994;7:222-9.

11. Ludwig SC, Kramer DL, Balderston RA, Vaccaro AR, Foley KF, Albert TJ. Placement of pedicle screws in the human cadaveric cervical spine: comparative accuracy of three techniques. Spine (Phila Pa 1976) 2000;25:1655-67.

12. Ebraheim NA, Xu R, Knight T, Yeasting RA. Morphometric evaluation of lower cervical pedicle and its projection. Spine (Phila Pa 1976) 1997;22:1-6.

13. Panjabi MM, Shin EK, Chen NC, Wang JL. Internal morphology of human cervical pedicles. Spine (Phila Pa 1976) 2000;25:1197-205.

14. Karaikovic EE, Kunakornsawat S, Daubs MD, Madsen TW, Gaines RW Jr. Surgical anatomy of the cervical pedicles: landmarks for posterior cervical pedicle entrance localization. J Spinal Disord 2000;13:63-72.

15. Yukawa Y, Kato F, Ito K, et al. Placement and complications of cervical pedicle screws in 144 cervical trauma patients using pedicle axis view techniques by fluoroscope. Eur Spine J 2009;18:1293-9.

16. Ishikawa Y, Kanemura T, Yoshida G, Ito Z, Muramoto A, Ohno S. Clinical accuracy of three-dimensional fluoroscopy-based computer-assisted cervical pedicle screw placement: a retrospective comparative study of conventional versus computer-assisted cervical pedicle screw placement. J Neurosurg Spine 2010; 13:606-11.

17. Lee SH, Kim KT, Abumi K, Suk KS, Lee JH, Park KJ. Cervical pedicle screw placement using the "key slot technique": the feasibility and learning curve. J Spinal Disord Tech 2012;25:415-21. 
18. Tofuku K, Koga H, Komiya S. Cervical pedicle screw insertion using a gutter entry point at the transitional area between the lateral mass and lamina. Eur Spine J 2012;21:353-8.

19. Tauchi R, Imagama S, Sakai Y, et al. The correlation between cervical range of motion and misplacement of cervical pedicle screws during cervical posterior spinal fixation surgery using a CT-based navigation system. Eur Spine J 2013;22:1504-8.

20. Fujibayashi S, Neo M, Yoshida M, Miyata M, Takemoto M, Nakamura T. Neck muscle strength before and after cervical laminoplasty: relation to axial symptoms. J Spinal Disord Tech 2010;23:197-202.

21. Park HW, Lee JK, Moon SJ, Seo SK, Lee JH, Kim SH. The efficacy of the synthetic interbody cage and Grafton for anterior cervical fusion. Spine (Phila Pa 1976) 2009;34:E591-5.

22. Ara T, Iizuka H, Sorimachi Y, et al. Evaluation of neck pain by using a visual analog scale before and after laminoplasty in patients with cervical myelopathy: relationship with clinical results. J Neurosurg Spine 2010;12:635-40.

23. Yukawa Y, Kato F, Ito K, et al. Laminoplasty and skip laminectomy for cervical compressive myelopathy: range of motion, postoperative neck pain, and surgical outcomes in a randomized prospective study. Spine (Phila Pa 1976) 2007;32:1980-5.

24. Lofgren H, Engquist M, Hoffmann P, Sigstedt B,
Vavruch L. Clinical and radiological evaluation of Trabecular Metal and the Smith-Robinson technique in anterior cervical fusion for degenerative disease: a prospective, randomized, controlled study with 2-year follow-up. Eur Spine J 2010;19:464-73.

25. McAviney J, Schulz D, Bock R, Harrison DE, Holland B. Determining the relationship between cervical lordosis and neck complaints. J Manipulative Physiol Ther 2005;28:187-93.

26. Baba H, Furusawa N, Imura S, Kawahara N, Tsuchiya $\mathrm{H}$, Tomita $\mathrm{K}$. Late radiographic findings after anterior cervical fusion for spondylotic myeloradiculopathy. Spine (Phila Pa 1976) 1993;18:2167-73.

27. Gore DR, Sepic SB. Anterior cervical fusion for degenerated or protruded discs. A review of one hundred forty-six patients. Spine (Phila Pa 1976) 1984;9:667-71.

28. Sakaura H, Hosono N, Mukai Y, Ishii T, Yoshikawa H. C5 palsy after decompression surgery for cervical myelopathy: review of the literature. Spine (Phila Pa 1976) 2003;28:2447-51.

29. Sasai K, Saito T, Akagi S, Kato I, Ohnari H, Iida H. Preventing C5 palsy after laminoplasty. Spine (Phila Pa 1976) 2003;28:1972-7.

30. Imagama S, Matsuyama Y, Yukawa Y, et al. C5 palsy after cervical laminoplasty: a multicentre study. J Bone Joint Surg Br 2010;92:393-400. 